\title{
Gender Quotas, Legislative Resistance and Non-Legislative Reform
}

\section{MALU A. C. GATTO}

Abstract: For over twenty years, gender quotas have been adopted and revised in Latin America and the world. This chapter investigates whether the type of authorship of gender quota adoptions/revisions is relevant to the strength of policy designs. The debate is unsettled: while some scholars portray male incumbents as interest-seeking actors, others view state actors as promoters of gender equality. Using a newly developed index of the strength of gender quota designs, I find support for the proposition that non-legislative actors are crucial in strengthening quota policies. I find that policy revisions carried out by non-legislative actors are, on average, stronger than those enacted by legislative actors and that non-legislative actors respond more rapidly to policy weaknesses than their legislative counterparts.

\section{Introduction}

Gender quota policies have gained the attention of international organizations and domestic policy-makers alike for their potential of overcoming gender inequality in parliaments throughout the world. Gender quotas are meant to facilitate the entry of women into politics by mandating a defined proportion of candidate nominations or seats in parliament to be reserved for women. ${ }^{1}$ In the last two decades, gender quotas have rapidly spread globally and have now been adopted as national-level policies in roughly 50 countries. This type of policy has been particularly prominent in Latin America, where, as of 2015, all democratic countries but one, Guatemala, have adopted national gender quota policies.

The literature identifies three general types of quotas: party quotas (individual parties voluntarily adopt an internally decided quota); legislated candidate quotas (a law mandates all parties in a given system to nominate the established proportion of female candidates); and, reserved seats (a law sets out a proportion of seats in parliament that can only be filled by women). ${ }^{2}$ All policies in Latin America fall under the 'legislated candidate quota' typology; nonetheless, variation in quota designs still exists. For example, policies adopted throughout the region have 
established quota requirements that range from 15 to 50 per cent. Furthermore, some policies adopted have included electoral sanctions for non-compliance, while others have been enforced through financial sanctions and many have not established sanctions at all.

As a type of affirmative action policy for women, gender quotas have the potential to intervene in the candidate recruitment process (otherwise exerted according to party discretion) and limit the space for male candidates - the vast majority of political incumbents and party leaders. Despite this, gender quotas adoptions have overwhelmingly taken place inside male-dominated congressional rooms. This pattern seems to defy long-standing assumptions of the rationality of career-driven politicians. According to this view, legislators would act to protect their seats by minimizing external competition - and not by adopting a policy that does the opposite: encourage the recruitment of candidates outside the existing pool.

The literature has generally tackled this puzzle in one of two ways: some scholars have posed that legislators are indeed self-motivated and, for this reason, adopt quotas as 'empty' gestures of their commitment to gender equality but purposefully design policies that lack the provisions necessary to enact real changes. Others have viewed the role of incumbents more favorably and argued that state actors can be active supporters of women's political representation and activists of change. ${ }^{3}$ In the current chapter, I contribute to this debate by analyzing the strength of gender quota designs vis-à-vis their origins. I judge the strength of gender quota policies not by their effective results, but by the provisions included in their designs. In assessing the origins of policies, I differentiating between processes enacted by legislative actors (e.g., electoral changes, encompassing constitutional reforms) and those carried out by non-legislative actors (e.g., executive decrees, judicial decisions). 
I hypothesize that because gender quotas go against the interests of legislative actors, strong gender quota designs are more likely to result from non-legislative processes.

I explore this theoretical proposition by coding and empirically analyzing gender quota policies, as originally introduced or subsequently modified by legislative or non-legislative processes. Using data from 40 instances of gender quota policy adoptions and revisions in Latin America, I show that non-legislative actors are responsible for strengthening crucial components of gender quota designs and that their intervention also considerably speeds up the process of design strengthening. For relying on descriptive statistics, the current chapter does not seek to exhaustively test the hypothesis posed, but, instead, to uncover previously hidden patterns in gender quota-related policy-making and highlight important questions on quota policy designs that remain largely unanswered. To the best of my knowledge, this is the first attempt to systematically and comparatively categorize specific provisions of gender quota policies as they pertain to the type of decision-making process that originated them. Throughout the chapter, the terms 'gender quota', 'quota', and 'quota policies' are used interchangeably.

I divide the chapter as follows: first, I briefly review the literature on gender quota adoption and strengthening. Subsequently, I describe the data used, a dataset that includes all cases of gender quota adoptions (and revisions) in Latin America. ${ }^{4}$ In the third section, I employ this dataset to analyze the association between the strength of gender quota designs and the type of process through which policies are originated. In conclusion, I summarize my findings and suggest potential areas for further study.

\section{Gender Quota Adoption and Strengthening}

Scholars generally identify three main forces behind the promotion, adoption, and strengthening of gender quotas worldwide: international organizations, transnational 
diffusion and learning, and the efforts of women's groups, female legislators and party leaders. ${ }^{5}$ Most studies agree that the growing popularity of gender quotas is, at least in part, a consequence of international norms and transnational values that emphasize the agenda of gender equality. Studies on gender quotas often claim that international conferences and recommendations such as the Convention for the Elimination of All Forms of Discrimination Against Women (CEDAW) from 1979 and the Beijing Platform for Action (PfA) from 1995, as well as the creation of UN Women in 2010, have all contributed to the popularity and spread of quotas throughout the world.

Similarly, transnational diffusion and learning have also been associated with processes of gender quota adoption and strengthening. This approach suggests that countries learn from each others' policy experiences, prompting policy imitation. In such explanations, policy strengthening results from countries' and policy-makers' engagement in information-sharing on quota provisions/design and observations of what types of policy provisions make quotas more or less effective in achieving their stated goals (i.e., increasing women's political representation).

Women's organizations are also often mentioned as the driving force behind the adoption of gender quotas as well as their subsequent strengthening revisions. Proponents of this view emphasize the importance of women's movements and argue that male-dominated elites do not push for gender quotas unless there is prior women's mobilization that presses for such policy. The proportions of women in parliament and party leadership have also been positively associated with the likelihood of a party to support gender quotas and lobby for stronger gender quota designs. 
Much less has been said about the factors that have the potential of negatively impacting the strength of quota designs. For instance, although many authors identify male legislators' resistance to gender quota adoption and/or policy-strengthening, few scholars focus on theorizing and empirically studying such resistance. The latter group generally poses that legislators act to minimize the impact of gender quotas on promoting change in elite renovation. To them, the actions of male incumbents represent empty gestures that do not produce strong or effective quotas. Gender quota policies, however, need not be adopted or revised by the very actors that are impacted by them: non-legislative actors may also intervene in processes of gender quota adoptions and strengthening. Baldez has been one of the few authors to place courts at the center of explanations on quota policy developments. According to her, judicial actors play a crucial role in legitimizing quota laws, given that the passing of gender quota legislation often prompts those resisting their adoption to challenge them constitutionally. Courts' willingness to assure the compliance of gender quotas and rule against non-compliance has also been described as important in effectively strengthening gender quota provisions. Furthermore, the role of executives in drafting gender quota-related legislation, providing guidance and resources to legislators supporting gender quotas, and enacting executive decrees to address policy design weaknesses has also been noted. ${ }^{6}$

Although the roles of international organizations, diffusion, and female actors within and outside of government have been vastly documented, much less attention has been dedicated to studying whether the type of decision-making process that lead to gender quota adoption/revision matters for policy design. To provide insights into this matter, the current chapter disaggregates the design of gender quota policies by provisions and type of origin. 


\section{Data}

One of the main challenges in carrying out this study is that it requires a measure of gender quota strength. Because I am interested in variation within cases for which gender quotas are in place, I use the index I developed to measure the strength of gender quota designs. The Index of Gender Quota Strength (IGQS) is composed of the different types of provisions identified in the literature as responsible for strengthening or weakening a gender quota policy.

Systematically comparing the strength of gender quota designs, however, is not an easy task. Many authors have contributed to the development of nuanced measures of gender quotas by suggesting frameworks that consider different policy provisions. Schwindt-Bayer, for instance, operationalizes quota strength by employing three characteristics of gender quota designs as separate independent variables, namely, 'quota size' (proportion of nominations reserved for women), 'placement mandate' (presence of mandate that establishes that female candidates should be placed in 'electable' positions), and 'enforcement mechanism'. ${ }^{7}$ Krook complements this package and argues that, when analyzing the effectiveness of gender quota policies, the aspects to investigate should be: ambiguity (whether language of the legislation is clear); requirements (size of quota demand); presence of sanctions for non-compliance; and, finally, 'perceived legitimacy' (presence of economic or political sanctions for non-compliance). ${ }^{8}$ Meanwhile, Jones categorizes gender quotas as 'well-designed' or 'poorly-designed' (i.e., 'lax'). According to him, 'lax' refer to policies with loopholes that essentially nullify or substantially diminish the application of gender quotas in practice. Aspects which render a design 'lax' include provisions that allow gender quotas to be avoided in cases in which primaries are conducted. ${ }^{9}$ I consider all of these discussions in the development of my indicator. 
In sum, from the types of provisions identified in the existing literature, I extract five dimensions that contribute to the strength of gender quota designs, namely: 1) size requirements; 2) placement mandates (i.e., ranking systems); 3) compliance mechanisms (i.e., sanctions) ; 4) office applicability, and 5) obstacles to implementation. For each dimension I create ordinal-level variables that range from 0 to 4 , with 0 representing 'no quota/lack of provision' and values 1 through 4 representing different gradations of provision strength from lowest (1) to highest (4). For example, on the scale of 'size requirements' a value of 1 refers to a quota between 20 and 29 per cent while a value of 4 refers to a quota of 50 percent. The IGQS compounds the scores of all five dimensions into a 21-point interval scale (in which 0 signifies the lack of a quota, 1 signifies the weakest and 21 the strongest gender quota designs). ${ }^{1}$ It is worth noting that I do not distinguish between parity regimes and quota laws, apart from issuing them different values on the parameter measuring 'size requirements'. Although I recognize the debate surrounding the philosophical differences between gender quota laws and parity regimes, I still treat them equally. The reasoning for this is simple: for the current work, gender quotas represent a type of policy with the potential of breaking the monopoly of political parties in candidateselection processes and displacing established elites to make room for political outsiders. Parity laws have the potential of prompting similar results.

For the task at hand, I also code the origins of gender quota policies, a process that is not clear-cut. Often, more than one type of actor is involved in the process of policy elaboration. Nonetheless, for the sake of empirical analysis, my coding assigns the origin/authorship of a given policy to the process/actors responsible for finalizing

\footnotetext{
1 The codebook explaining the development of indicator and coding of individual quota policies can be accessed at: http://www.malugatto.com.
} 
it. For instance, a gender quota policy requiring legislative approval to be enacted is counted as originating from the legislature, even if non-legislative actors were involved in earlier stages of the the decision-making process. Furthermore, I only consider policies that directly pertain to gender quotas for legislative office. Other gender quota-related policies, including quotas for other government offices, are not included in the current analysis. This variable is coded 0 for policies enacted by legislative actors and 1 for those enacted by non-legislative actors.

To build the dataset used, I first relied on secondary sources to identify relevant policies and complete a list of decision-making processes that affected gender quota policy designs in law and practice. These sources include the Global Database of Quotas for Women, ${ }^{10}$ the Observatório de Género of CEPAL,,${ }^{11}$ as well other country-specific secondary sources. I then used primary sources (e.g., congressional decisions, executive decrees, judicial rulings) to individually hand-code each policy in accordance with the operationalization guidelines outlined for the IGQS.

\section{Results}

A total of 41 procedures of gender quota adoption and revision have taken place in Latin America since 1990; this includes policies resulting from legislative processes, executive decrees and judicial decisions. Of the 17 countries from the region that have adopted some type of gender quota, 12 have subsequently revised their respective policies at least once. Although the overwhelming majority of original gender quota policies have been adopted by legislatures, either as specific bills or as parts of larger electoral reforms, gender quota policy revisions have sometimes taken place outside congressional rooms. That is, 16 original gender quota policies have been introduced through legislative processes, one by executive decree and one by 
judicial ruling; ${ }^{12}$ meanwhile, legislators have been responsible for 17 subsequent policy revisions, executives for two and courts for four. ${ }^{13}$ This means that nonlegislative actors were responsible for 11.1 per cent of original gender quota adoptions and 26 per cent of revisions, including one quota retraction.

Figure 1 provides an overview of how values of the IGQS are distributed across all 40 policies and breaks down this distribution by each of IGQS's individual components. As illustrated, the distribution of the values of the IGQS is skewed left, meaning that policies in the region most frequently score higher than lower values on the IGQS scale; the IGQS produces a mean of 11.5 and a median of 12, also reflecting this distributional tendency towards higher values.
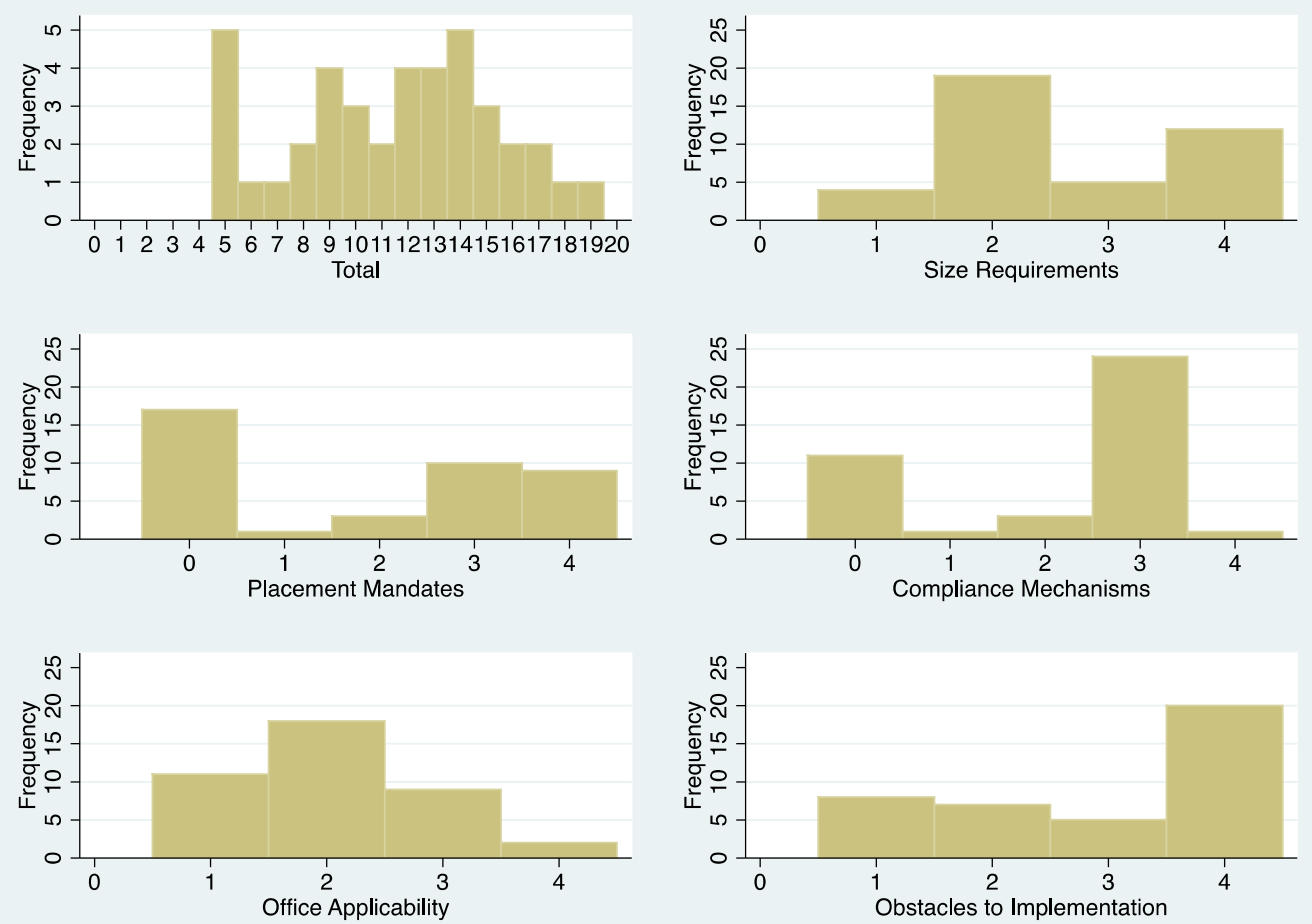

Figure 1. Values of the IGQS and its individual components, as distributed in Latin America

Source: developed by author using own data.

Nonetheless, only two of scales of the individual components that make up the IGQS produce means above the scale midpoint (2.5). The scale for size requirements produces a mean of 2.625 , while the scale of obstacles for implementation produces a 
mean of 2.925 . This suggests that these are the scales that, on average, mostly contribute to the strength of gender quota designs in Latin America. This makes sense given that many gender quotas have been recently transformed into parity regimes, thus increasing the size requirements of policy designs, and that many original quotas have been revised (through legislative means or by executive decrees, and court resolutions) to close design loopholes.

Despite this seemingly positive snapshot, a number of authors have depicted early gender quota adoptions in Latin America as symbolic gestures to show-case legislators' commitment to gender equality while avoiding increased electoral competition. Others have posed that although presumably weak, early gender quota policies served as the basis of entrance for women in parliament, who could then challenge weak designs and strengthen quotas from within the system. ${ }^{14}$ As figure 2 illustrates, weak gender quota designs have indeed been more common among early adopters, with no country other than Nicaragua adopting a quota design scoring less than 10 on the IGQS scale after 1998.

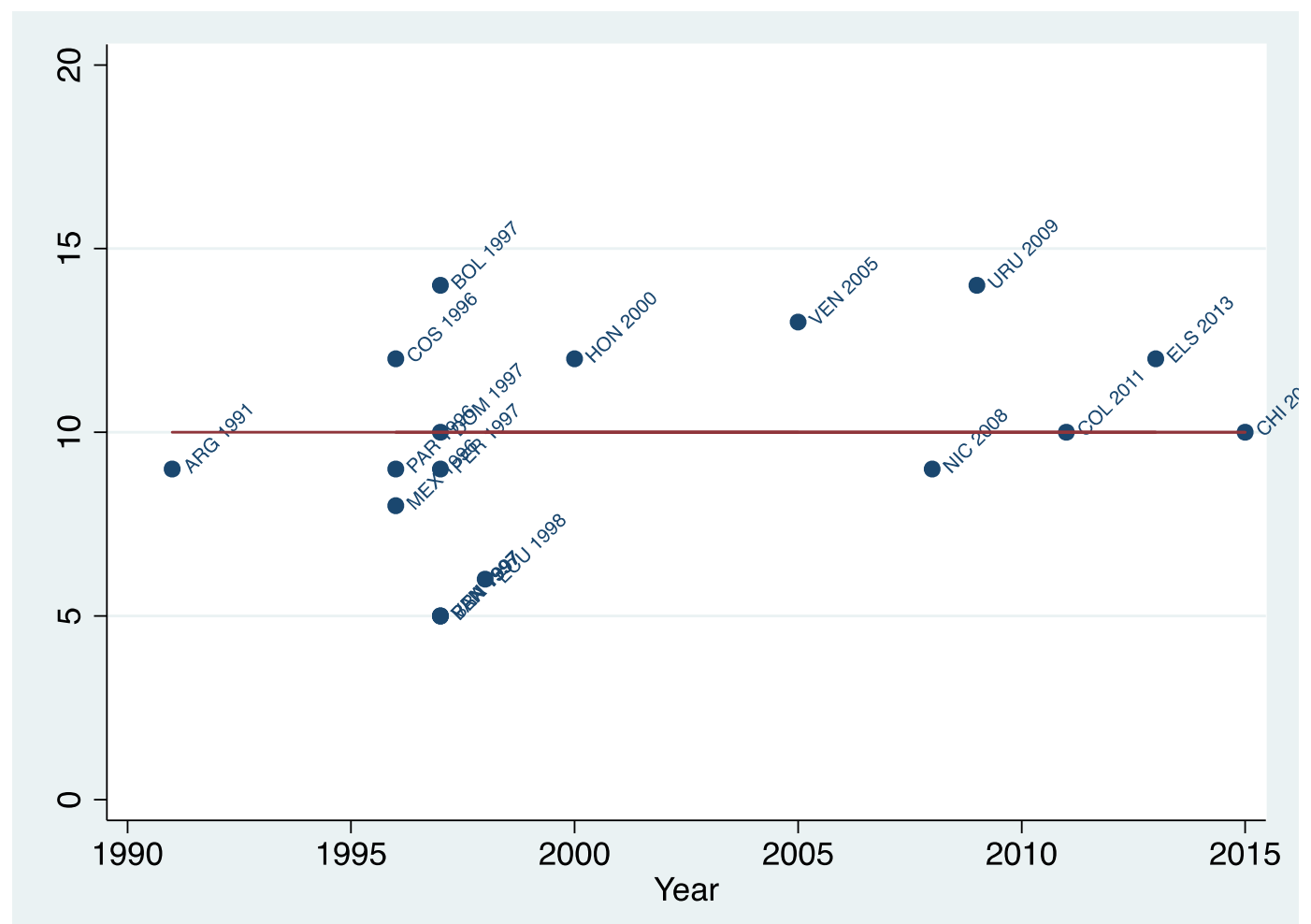


Figure 2. Strength of original gender quota policy designs in Latin America, as measured by the IGQS

Source: developed by author using own data.

Among early adopters only one has never revised its quota (Paraguay). All other countries that adopted a quota before 2000, (Argentina, Bolivia, Brazil, Costa Rica, the Dominican Republic, Ecuador, Mexico, Panama, Peru, and Venezuela) have since amended their original policy designs. Together, these eleven countries have enacted a total of 20 revisions (and one retraction in Venezuela). Of these, 14 were enacted by the legislature: increasing quotas' size requirements in eight instances, placement mandates in six, compliance mechanisms (i.e., sanctions) in three, extending office applicability in four cases, and diminishing or completely closing loopholes twice.

Albeit less frequently, legislative revisions have also been used to weaken gender quota designs: in the Dominican Republic (2000), a reform repealed the quota from the Senate, leading to a decrease in my measure of office applicability; in two other cases, Mexico (2002) and Ecuador (2000), revisions created more obstacles to implementation. Two late-adopters also reformed their original quotas though legislative means: Honduras and Nicaragua. Honduras' engagement in legislative revision in 2004, also led to the weakening of its quota, which was once again restored and strengthened in $2012 .{ }^{15}$ In the same year, the Nicaraguan legislature also strengthened its quota through legislative reform. Although gender quota revisions enacted through legislative means have been frequent, the intervention of non-legislative actors has been less common. Only six policy revisions enacted in the region have not been led by legislative actors; of these, one retracted the existing quota; none addressed size requirements; two strengthened placement mandates; one enacted sanctions for non-compliance; two increased office reach; and, two addressed loopholes. This brief summary suggests that the role of legislative actors in 
strengthening gender quota legislation has been extremely prominent and that nonlegislative actors may have had only a marginal influence in this process.

Simple descriptive statistics, however, show that although reforms led by nonlegislative actors have been few, they have been significant in magnitude. Table 1 summarizes the changes in policy strength for the IGQS and all of its individual components, as enacted by legislative and non-legislative actors. The values below refer to the means of policy differences, disaggregated by the type of policy authorship. These values are calculated by first taking the difference in policy strength between a given policy revision and the score of the policy that preceded it (e.g., the Mexican quota policy of 1996 received a score of 8 and its 2002 revision a score of $11 ; 11-8=6=3$, thus the difference in policy strength as enacted by revision equals three), adding-up all of the policies differences and then dividing the result by the number of policies considered.

When disaggregated by type of policy origin, this measure allows for the analysis of the relationship between the substantiality of quota revisions and their respective authors. Engaging in this exercise, I find that, on average, non-legislative reforms have led to greater strengthening of policy designs three of the five dimensions of the IGQS: compliance mechanisms, office applicability, and obstacles to implementation. Although the mean for the overall IGQS is higher for the distribution of cases enacted through legislative action, this is driven by changes in placement mandates and size requirements; this suggests that although legislative reforms are more frequent, they are also less ambitious in addressing weaknesses in policy designs - especially in regards to compliance mechanisms and loopholes, aspects considered by the literature as crucial for the effective implementation of gender quotas. These findings could be a consequence of the tension between the unwillingness of male legislators to adopt strong gender quotas and increase 
electoral competition and the pressure felt by executive and judicial actors to uphold normative values promoted by domestic and international pressure groups.

Table 1. Strength of Policy Revisions in Latin America, as measured by changes in the IGQS and its individual component scales

\begin{tabular}{lcccccc}
\hline & IGQS & Size & Placement & Compliance & Office & Obstacles \\
\hline Mean of $\Delta$ & 2.68 & 0.45 & 1.23 & 0.41 & 0.27 & 0.23 \\
Mean of $\Delta$ Legislative & 2.70 & 0.58 & 1.35 & 0.35 & 0.18 & 0.06 \\
Mean of $\Delta$ Non-Legislative & 2.60 & - & 0.80 & 0.60 & 0.60 & 0.80 \\
\hline
\end{tabular}

Note: based on 22 cases: 17 enacted through legislative means and 5 by nonlegislative actors (not considering case of quota retraction in Venezuela).

Non-legislative actors have been particularly important where original adoption has been the weakest. Brazil, Panama, Ecuador, Mexico, and Venezuela originally adopted quotas with very weak designs; Brazil, Panama and Venezuela produced original IGQS scores of five, while Ecuador and Mexico produced designs of scores six and eight, respectively. In three cases, Brazil, Mexico, and Venezuela original policies were reformed (or substituted, in the case of Venezuela) by stronger designs enacted by non-legislative actors. Brazil adopted a quota policy 30 per cent for the lower house of its national congress in 1997. Despite the efforts of female legislators and women's groups, the quota was only approved by the Brazilian legislature after the inclusion of loopholes: in passing a 30 per cent gender quota, parties managed to simultaneously increase the proportion of candidacies a party could nominate from 100 to 150 per cent, as well as given the possibility of not complying with the gender quota in case not all candidacies were filled. Needless to say, the inclusion of this provision drastically challenged the implementation of the Brazilian gender law. The quota was only reformed again in 2009, when the executive established a tri-partite commission to draw proposals to be submitted as part of a larger electoral reform; many of the commission's proposals were stripped down and weakened during legislative debates, but their proponents managed to secure changing the 
language of the legislation from 'reserve' to 'fill', thus implying that it was no longer enough for parties to comply the quota by 'reserving' extra candidacies for female candidates but not recruiting women to fill them. This change gave way for non-legislative actors to intervene more directly in 2010; by ruling that party lists that did not include at least 30 per cent of female candidates would not be registered, the electoral tribunal stipulated electoral sanctions for political parties that did not comply with the quota.

In Mexico, the actions of the judiciary were even more emphatic in addressing policy loopholes. Mexican political parties had been avoiding gender quota compliance in two ways: first, by selecting candidates via party primaries, thus forgoing the need to respect the quota, and second by electing women who, upon election, would step-down and be replaced by men (Juanitas, as they became known). In 2011, Mexico's electoral court ruled that neither tactic could be used to avoid the gender quota, closing the loopholes that for years challenged the implementation of the Mexican quota law. Finally, in Venezuela, the original quota repealed by the constitutional court in 2000 , was replaced by an 11 points stronger one enacted via a judicial ruling of the Venezuelan electoral tribunal in 2005. Through legislative means, Panama and Ecuador were also able to strengthen the policy designs of their original quota policies. Nevertheless, it took Panama two policy revisions through the legislature to strengthen its original policy by only three points on the IGQS scale - resulting in what is today one of the weakest gender quota policies in the region. Ecuador, on the other hand, managed to extensively revise its original quota, increasing its policy strength from seven to 18 in just two years, a process which was done as part of the country's efforts to establish general election laws in $2000 .^{16}$

Non-legislative actors have also been more quick to address weaknesses and/or loopholes in gender quota designs than legislative actors. While revisions enacted by legislative actors have taken an average of 5.88 years to take place, revisions by non- 
legislative actors have happened on average within 3.5 years of an earlier policy. Delays to act can have real consequences for quota policy design. This can be illustrated by a number of cases, Honduras being the most obvious. Honduras first adopted a gender quota in 2000, scoring 12 on the IGQS scale. It then enacted its first reform in 2004, weakening the design of its original policy by decreasing the quota size requirement from 50 per cent to be reached gradually to 30 per cent and by getting rid of its ranking system. Its subsequent reform, concluded by the legislature in 2012, repaired what had been lost in 2004 and produced a quota 5 points stronger than the original design established in 2000. In sum, through legislative revisions, it took 12 years for Honduras to strengthen its policy design by five points. The Peruvian gender quota, originally adopted in 1997 with a score of nine, has undergone two legislative reforms, one in 2000 and another in 2003; in the course of six years the policy was strengthened by five points, but policy developments have stalled ever since, making the Peruvian quota comparatively weak by current standards.

Finally, the contribution of non-legislative actors to the strengthening of gender quota designs goes well beyond their role in enacting change through executive decrees or judicial decisions that directly modify gender quota provisions. In fact, much of the influence of non-legislative actors in strengthening gender quota policies have not been captured in my coding. This results from two factors. First, my coding assigns the authorship of a given policy revision to the actors that finalized/enacted it, meaning that actors' behavior at other stages of policy-making are not accounted for. Policy-making is much more complex, however, and multiple types of actors are often involved at different stages of the process. For instance, an executive may introduce a policy proposal to be considered in a legislature, which then amends and votes on it. In such a scenario, although the executive had a crucial role in prompting the process of policy-making, the policy would still be coded as originating from the legislature; this, of course, minimizes the 
impact of non-legislative actors in my analysis. This is a particular problem given that the hypothetical scenario described is not uncommon. Most recently, this has taken place in Mexico, when in celebration of the $60^{\text {th }}$ anniversary of women's suffrage, President Enrique Peña Nieto presented a proposal for a parity law. While introducing his proposal on 11 October 2014, Peña Nieto received a standing ovation and stated that he had 'no doubt [the policy] would be easily adopted' by congress. ${ }^{17}$ Indeed, the Mexican congress incorporated his proposal into a larger electoral reform and approved it only months later. In this example, despite the fact that the reform was largely influenced by the executive, the policy was still coded as originating from the legislature, given that it required the body's approval. Similar policy processes have also taken place in other countries, such as in Chile (2014) and Costa Rica (1990 and 2007).

The second way in which my empirical analysis further minimizes the impact of non-legislative actor is by not accounting for the importance of constitutional legitimacy to the implementation of gender quota policies. Challenging the constitutionality of gender quota laws has been a widespread tactic used by political parties and male incumbents to resist the adoption and implementation of gender quotas. In this sense, the willingness of courts to uphold the legitimacy of quota provisions and oversee their compliance has been crucial. Baldez argues that the Mexican Supreme Court's decision to support the constitutionality of gender quotas was one of the main factors in securing the effectiveness of the policy and in making it difficult for the opposition to prevent the policy from being implemented. ${ }^{18}$ In some instances, however, contradicting court resolutions and the reluctance of electoral courts to get involved have also been observed to impact the implementation of quota policies in detrimental ways. On March 2000, Colombia’s Constitutional Court deemed a bill already approved by Congress unconstitutional for including 30 per 
cent candidate quota; although the Court approved other quota provisions in the bill, it interpreted that a legislated candidate quota would infringe on the autonomy of parties. In May 2000, Law 581 was enacted, instituting gender quotas for non-elected government offices. This decision set-back the process of adoption of gender quotas for legislative office by many years: Colombia only managed to adopt a legislated candidate quota in 2011, after making amendments to its constitution in 2009. These examples show that electoral and higher courts, and their respective interpretations of gender quota policies are crucial in both legitimizing and facilitating the implementation of gender quotas (or accomplishing the very opposite).

\section{Conclusion}

For over twenty years, gender quotas have been adopted and revised in Latin America and the world. The spread of this institutional innovation was accompanied by extensive academic research. The literature has made incredible progress in documenting and analyzing the roles of international organizations, transnational diffusion, women's groups and female parliamentarians in processes of gender quota adoption and revision. This focus, however, has been at the cost of under-theorizing the impact of male resistance, as well as executive and judicial actors.

The current chapter hypothesizes that the intervention of non-legislative actors in processes of gender quota adoption and revision produce greater positive outcomes to the strength of policy designs than when legislators are left to act on their own. This could result from the resistance of male parliamentarians to strengthen gender quota provisions and risk increasing their electoral competition. The reluctance of congressional incumbents to pass strong quota legislation could then give ground for 
executive and judicial actors to address policy weaknesses and strengthen gender quota policies.

By descriptively comparing and contrasting the overall strength of gender quota policies and its five individual components, I found support for the proposition that executive and judicial actors play a crucial role in strengthening gender quota policies. This conclusion derives from the following observations: first, policy revisions carried out by non-legislative actors are, on average, stronger than those enacted by legislative actors for three of the five components of the IGQS, even though the latter has been the most frequent; second, non-legislative actors respond more rapidly to policy weaknesses than their legislative counterparts. Furthermore, the impact of non-legislative actors cannot be fully grasped by my empirical analysis: their role also extends to, among other things, publishing policy recommendations, drafting and presenting bills to the legislature, providing expertise to legislative actors, and granting constitutional legitimacy to the status of quota laws.

The conclusions drawn at this stage are only exploratory and, more importantly, can only speak to the observable implications expected as a consequence of my hypothesis holding; in other words, while the results are aligned with my expectations about the behavior of legislative and non-legislative actors, my findings do not confirm the assumptions I make about the incentives for actors' behaviors (i.e., that legislative actors seek to contain quota strength in order to protect their seats, while non-legislative actors aim to promote gender quotas for exogenous and/or value-oriented reasons).

Given that my conclusions are, thus far, only grounded in theoretical developments and descriptive statistics, they should only be interpreted as providing exploratory ground for future research. This is not to say that the findings presented 
should not be taken into account: the dynamics between legislative and nonlegislative processes have rarely been researched in the context of gender quota adoptions and revisions, and the patterns uncovered certainly deserve further investigation. Combined, my observations suggest that, although gender quotas have been studied extensively, many questions remain unanswered. For instance: is the involvement of non-legislative actors in processes of gender quota adoption and revision a consequence of the institutional capacity of each government branch, or a response to the failure of legislatures to properly address and/or comply with the normative commitments of a given government? How do quotas for other branches of government (and the descriptive representation of women in key position in the executive and court system) impact the involvement of non-legislative actors in processes of gender quotas for legislative office? These questions illustrate the fruitful ground for research that remains under-explored and highlight the need for greater insight into the impact of the roles of specific actors and policy-making processes to the strength of gender quota designs.

\section{References}

Lisa Baldez, 'Elected bodies: The gender quota law for legislative candidates in Mexico' [2004] 44(2) Legislative Studies Quarterly 232-4.

Mark Jones, 'Gender quotas, electoral laws, and the election of women: Evidence from the Latin American vanguard' [2009] 42(1) Comparative Political Studies 62-3.

Mona Lena Krook, Quotas for women in politics: Gender and candidate selection reform worldwide (Oxford University Press 2009) 6-9.

Jennifer Piscopo, 'States as Gender Equality Activists: The Evolution of Quota Laws in Latin America' [2015] 57(3) Latin American Politics and Society 27-49.

Leslie Schwindt-Bayer, 'Making Quotas Work: The Effect of Gender Quota Laws On the Election of Women' [2009] 34(1) Legislative Studies Quarterly 5-28. 
${ }^{1}$ Although quotas can be (and have been) applied to many spheres, this chapter only covers policies for elected legislative office.

${ }^{2}$ Mona Lena Krook, Quotas for women in politics: Gender and candidate selection reform worldwide (Oxford University Press 2009) 6-9.

${ }^{3}$ For a summary of the debate, see: Jennifer Piscopo, 'States as Gender Equality Activists: The Evolution of Quota Laws in Latin America' [2015] 57(3) Latin American Politics and Society 27-49.

${ }^{4}$ The countries included in the analysis are: Argentina, Bolivia, Brazil, Chile, Colombia, Costa Rica, Dominican Republic, Ecuador, El Salvador, Honduras, Mexico, Nicaragua, Panama, Paraguay, Peru, Uruguay, and Venezuela. Guatemala does not have a gender quota and is consequently no included.

${ }^{5}$ For a review of the literature, see: Krook 9-12; Lisa Baldez, 'Elected bodies: The gender quota law for legislative candidates in Mexico' [2004] 44(2) Legislative Studies Quarterly 232-4.

${ }^{6}$ See: Baldez; Piscopo; Krook 172.

${ }^{7}$ Leslie Schwindt-Bayer, 'Making Quotas Work: The Effect of Gender Quota Laws On the Election of Women' [2009] 34(1) Legislative Studies Quarterly 5-28.

${ }^{8}$ Krook 11.

${ }^{9}$ Mark Jones, 'Gender quotas, electoral laws, and the election of women: Evidence from the Latin American vanguard' [2009] 42(1) Comparative Political Studies 62-3.

${ }^{10}$ The database can be accessed at: http://www.quotaproject.org. Accessed on 20 December 2015.

${ }^{11}$ The database can be accessed at:

http://www.cepal.org/cgibin/getprod.asp?xml=/oig/noticias/paginas/5/36135/P36135.xml\&xsl=/oig/tpl/ p18f.xsl\&base=/oig/tpl/top-bottom-decisiones.xs. Accessed on 20 December 2015.

${ }^{12}$ I consider Venezuela to have had two cases of 'original' gender quota adoptions; that is because I consider original adoption as a policy enacted when no other gender quota policy was in place. Given that the first gender quota policy in Venezuela was retracted in 2000, the 2005 policy that reinstated the quota is also coded as an original policy.

${ }^{13}$ My analyses exclude the sentence enacted by the Venezuelan Constitutional Court in 2000, which deemed the original 1997 policy unconstitutional. I exclude this case because given that I am only concerned with policy designs, including a case in which a gender quota policy is lacking would only add noise to the analysis.

${ }^{14}$ Piscopo 36; Baldez 235.

${ }^{15}$ The latest quota revision in Honduras has been characterized elsewhere as a consequence of executive decree. In fact, all gender-related policies enacted in Honduras (Decreto No 34-2000; Decreto No 44-2004 and Decreto No 54-2012) have been initiated and finalized in the National Congress. The 2012 law resulted from a bill presented by Congresswoman Gillian Guifarro Montes. The confusion might have resulted from the fact that Honduras two types of decretos (decrees), executive and legislative.

${ }^{16}$ Note that quota policies originally drafted by non-legislative actors have also been strong. The original parity law enacted by executive order (Decreto No 29-2010) in Nicaragua in 2010 scored 11 on the IGQS scale, while the Venezuelan quota enacted by the electoral court in 2005 (CNE Resolución No 050401-179) scored 17. Given that non-legislative intervention has only led to the adoption of original gender quotas twice, I do not discuss this aspect at length.

${ }^{17} \mathrm{Parts}$ of his speech can be watched at: http://mexico.cnn.com/nacional/2013/10/11/pena-nietopropone-que-el-50-de-candidaturas-al-congreso-sean-de-mujeres. Accessed on 20 December 2015.

${ }^{18}$ Baldez, 2004: 234, 244-246. 